\title{
Assessment of C-reactive Protein Level and Efficacy of Diclofenac Sodium and Mefenamic Acid in Relieving Pain in Mandibular Impacted Third Molar Surgery
}

\author{
Rohit Singh ${ }^{1}$, Cheranjeevi Jayam $^{2}$, Revati Singh ${ }^{3}$, Jazib Nazeer $^{4}$, Mohammad Asad Iqubal $^{5}$, Supriya Singh $^{6}$
}

\begin{abstract}
Aim: To compare the efficacy of diclofenac sodium and mefenamic acid in relieving pain in mandibular impacted third molar surgery and to assess the level of the C-reactive protein (CRP) level.

Materials and methods: This study was conducted on 90 patients of impacted mandibular third molars. All patients were administered with $2 \%$ lignocaine with 1:80,000 adrenaline, and surgical removal of impacted third molar was done following the standardized surgical procedure by a single oral surgeon. Patients were divided into two groups of 45 each. In group I, patients were prescribed 50 mg diclofenac sodium and in group II patients were prescribed $500 \mathrm{mg}$ mefenamic acid for three times a day for 3 days. The CRP level was again evaluated after 3 days of analgesics. Pain was assessed using the visual analog scale (VAS).

Results: The mean VAS was 2.58 in group I and 3.46 in group II, which was statistically considerable $(p<0.05)$. The mean CRP level postoperatively in group I was 15.7 and after 3 days was 27.2 in group I, whereas it was 25.1 postoperatively and 31.5 after 3 days in group II.

Conclusion: Authors found that diclofenac sodium as useful as mefenamic acid. The CRP level was raised significantly following surgery, thus reflecting that it is an indicator of inflammation.

Clinical significance: Diclofenac sodium can be used to relieve pain. The CRP level evaluation can be helpful to assess inflammation following surgery.

Keywords: Diclofenac, Mefenamic acid, Third molar.

The Journal of Contemporary Dental Practice (2021): 10.5005/jp-journals-10024-2852
\end{abstract}

\section{INTRODUCTION}

The most common impacted teeth are mandibular third molar after canine and premolars. Among different type of impactions, mesioangular impaction is commonly encountered as seen $>35 \%$ of cases. Thus, disimpaction of the impacted mandibular third molar is a routine procedure in oral surgery. ${ }^{1}$

Surgical extraction of the mandibular third molar is often preceded by pain, swelling, and trismus. All features may vary from person to person and is considered to be subjective in nature. Several pro-inflammatory mediators are actively released leading to an inflammatory response. ${ }^{2}$

Pain management following mandibular third molar impaction is of paramount importance. Analgesics are given before the surgical procedure and also administered after treatment. It significantly reduces inflammation and plays an important role in pain control. The aim is to relieve pain during and after the procedure. ${ }^{3}$ Among various analgesics, diclofenac is commonly used nonsteroidal antiinflammatory drugs (NSAIDS). It is an anti-inflammatory and potent analgesic. As compared to other NSAIDS, diclofenac sodium is more effective in reducing pain and swelling. There are different routes of administration such as soft gel, tablet, and intravenous infusion. ${ }^{4}$

Of its three dispensable forms, namely intravenous infusion, soft gel, and tablets, per-oral tablets were favored because of the limited duration of action and higher cost of treatment with infusions and gel. ${ }^{5} \mathrm{C}$-reactive protein (CRP) is commonly released during surgical procedures such as disimpaction of the mandibular third molar. It is considered a reliable marker of tissue injury and inflammation. To overcome signs and symptoms of patients, NSAIDS are used. ${ }^{6}$ In this study, we compared the efficacy of diclofenac sodium and
${ }^{1}$ Department of Prosthodontics, Crown, Bridge and Implantology, Patna Dental College and Hospital, Bihar, India

${ }^{2}$ Department of Dentistry, All India Institute of Medical Sciences, Mangalagiri, Andhra Pradesh, India

${ }^{3}$ Department of Dentistry, Patna Medical College and Hospital, Patna, Bihar, India

${ }^{4}$ Department of Oral Pathology, Patna Dental College and Hospital, Patna, Bihar, India

${ }^{5}$ Department of Oral Medicine and Radiology, Patna Dental College and Hospital, Patna, Bihar, India

${ }^{6}$ Private Practitioner, Patna, Bihar, India

Corresponding Author: Cheranjeevi Jayam, Department of Dentistry, All India Institute of Medical Sciences, Mangalagiri, Andhra Pradesh, India, Phone: +91 7903154108, e-mail: cheranjeevij@gmail.com

How to cite this article: Singh R, Jayam C, Singh R, et al. Assessment of C-reactive Protein Level and Efficacy of Diclofenac Sodium and Mefenamic Acid in Relieving Pain in Mandibular Impacted Third Molar Surgery. J Contemp Dent Pract 2021;22(1):39-41.

Source of support: Nil

Conflict of interest: None

mefenamic acid in relieving pain in mandibular impacted third molar surgery and to assess the level of CRP.

\section{Materials and Methods}

This study comprised of 90 patients who visited the department for the management of impacted mandibular third molars. Inclusion 
CRP Level and Diclofenac Sodium and Mefenamic Acid

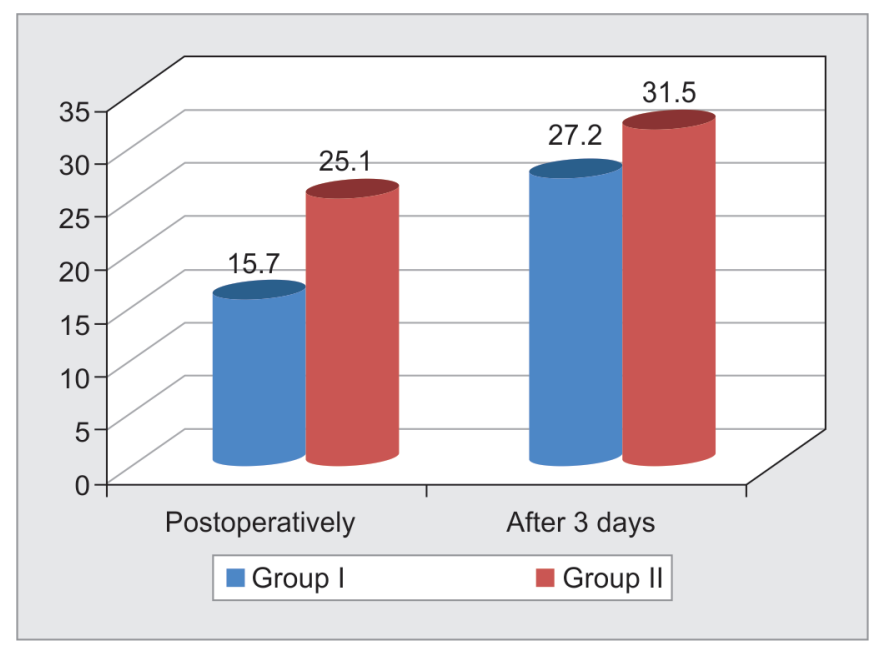

Fig. 1: Assessment of the CRP level in both groups

criteria of the study were patients $>18$ years of age with any type of impaction such as mesioangular, distoangular, horizontal, and vertical, with patients giving consent. Exclusion criteria was patients $<18$ years of age, patients on antibiotic, and pregnant women. College ethical approval was taken (Fig. 1).

Demographic data were recorded. A thorough clinical examination was done followed by radiographic evaluation with intraoral and panoramic radiographs. All patients were administered with $2 \%$ lignocaine with 1:80,000 adrenaline, and surgical removal of the impacted third molar was done following the standardized surgical procedure by a single oral surgeon.

The $2 \mathrm{~mL}$ venous blood was collected in a sterile glass test tube and serum was separated. Agglutination was assessed for the assessment of CRP. Patients were randomly classified into two groups based on the drug used. In group I, patients were prescribed $50 \mathrm{mg}$ diclofenac sodium and in group II patients were prescribed $500 \mathrm{mg}$ mefenamic acid for three times a day for 3 days. The CRP level was again evaluated after 3 days of analgesics. Pain was assessed using the visual analog scale (VAS).

Data thus obtained were entered in MS Excel for statistical analysis using the SPSS 19.0 version. The VAS score and level of CRP were determined (Chi-square test). The level of significance was set at 0.05 (Table 1).

\section{Results}

Group I patients received diclofenac sodium and group II received mefenamic acid. Each group comprised of 45 patients. Table 2 shows that mean VAS was 2.58 in group I and 3.46 in group II. The VAS score between groups was found to be significant $(p<0.05)$.

The mean CRP level postoperatively in group I was 15.7 and after 3 days was 27.2 in group I whereas it was 25.1 postoperatively and 31.5 after 3 days in group II, and a significant difference was found $(p<0.05)$.

\section{Discussion}

Surgical disimpaction of mandibular third molar is the routine procedure in oral surgery. Even with taking all the precautionary measures, pain and swelling cannot be overcome, thus the use of NASIDS becomes essential in these patients. ${ }^{7}$ Diclofenac sodium in dosage of $400 \mathrm{mg}$ causes reduction in swelling and found to
Table 1: Distribution of patients

\begin{tabular}{lll}
\hline Groups & Group I & Group II \\
\hline Drug & Diclofenac sodium & Mefenamic acid \\
Number & 45 & 45 \\
\hline
\end{tabular}

Table 2: Assessment of pain in both groups

\begin{tabular}{llll}
\hline Groups & Mean & $X^{2}$ & $p$ value \\
\hline Group I & 2.58 & 12.50 & 0.01 \\
Group II & 3.46 & & \\
\hline
\end{tabular}

Table 3: Assessment of CRP level in both groups

\begin{tabular}{lcll}
\hline Groups & Group I & Group II & p value \\
\hline Postoperatively & 15.7 & 25.1 & 0.001 \\
After 3 days & 27.2 & 31.5 & 0.05 \\
$p$ value & 0.01 & 0.02 & \\
\hline
\end{tabular}

be beneficial in these patients. There is significant reduction in pain also. In case of severe pain, mefenamic acid is preferred. ${ }^{8}$ We compared the efficacy of diclofenac sodium and mefenamic acid in relieving pain in mandibular impacted third molar surgery and to assess the level of CRP (Table 3).

We included 90 patients, which were divided into two groups. Group I patients received diclofenac sodium and group II received mefenamic acid. Akbulut et al. ${ }^{9}$ conducted a study on 42 patients with impacted mandibular third molars, who were divided into the diclofenac potassium group, the naproxen sodium group, and the etodolac group. The VAS for pain was recorded following surgical removal of the third molar postoperatively. Diclofenac potassium had better results than naproxen sodium and etodolac; however, differences were nonsignificant. The diclofenac potassium group had less swelling on postoperative 2 nd day as compared to other groups.

We found that mean VAS was 2.58 in group I and 3.46 in group II. We found that the mean CRP level postoperatively in group I was 15.7 and after 3 days was 27.2 in group I whereas it was 25.1 postoperatively and 31.5 after 3 days in group II.

Mony et al. ${ }^{10}$ in their study divided 50 patients into the ketorolac group and the diclofenac sodium group. Postoperative pain was recorded for 3 days using VAS. The ketoralac group had 5.48 hours' time taken for pain perception whereas the diclofenac sodium group had 4.9 hours. The mean number of tablets taken by the Ketorolac group was 3.24 and the diclofenac sodium group was 4.04 .

Salgia et al. ${ }^{8}$ in their study included 60 patients who received $500 \mathrm{mg}$ mefenamic acid in group I, $400 \mathrm{mg}$ ibuprofen in group II, and $50 \mathrm{mg}$ diclofenac in group III. C-Reactive protein was evaluated at baseline and postoperatively after third molar impaction surgery. Authors found nonsignificant difference in duration of surgery. Author found significant increase in CRP levels after 72 hours.

El-Sharrawy et al. ${ }^{11}$ evaluated the serum level of CRP after third molar extraction. It was found that the CRP level had increased to its maximum after 72 hours and returned to the normal value within a week. There have been various NSAIDS in the management of postoperative pain and inflammation in patients following third molar impaction surgery. It acts by inhibition of arachidonic acid production by inhibiting cyclooxygenase enzyme, which in turn prevents production of prostaglandin and thromboxanes. 
The limitation of study is small sample size and only diclofenac sodium and mefenamic acid are compared.

\section{Conclusion}

Authors found that diclofenac sodium is as useful as mefenamic acid. The CRP level was raised significantly following surgery, reflecting that it is an indicator of inflammation.

\section{References}

1. Kumar-Pillai A, Thomas S, Paul G, et al. Incidence of impacted third molars: a radiographic study in people's hospital, Bhopal, India. J Oral Biol Craniofac Res 2014;4(2):76-81. DOI: 10.1016/j.jobcr.2014. 04.001.

2. Tuzuner-Oncul AM, Yazicioglu D, Alanoglu Z, et al. Postoperative analgesia in impacted third molar surgery: the role of preoperative diclofenac sodium, paracetamol and lornoxicam. Med Princ Pract 2014;20(5):470-476. DOI: 10.1159/000327658.

3. Bailey E, Worthington $\mathrm{H}$, Coulthard P. Ibuprofen and/or paracetamol (acetaminophen) for pain relief after surgical removalof lower wisdom teeth, a cochrane systematic review. Br Dent J 2014;216(8):451-455. DOI: 10.1038/sj.bdj.2014.330.

4. Nazar MN, Puthiriraj V. Analgesics following mandibular third molar surgery. IJPCR 2014;6:13-19.

5. Yamashita Y, Sano N, Shimohira D, et al. Parallel group comparison study of celecoxib with loxoprofen sodium in third mandibular molar extraction patients. Int J Oral Maxillofac Surg 2014;43(12):1509-1513. DOI: 10.1016/j.ijom.2014.09.002.

6. Zupelari-Goncalves P, Weckwerth GM, Calvo AM, et al. Efficacy of oral diclofenac with or without codeine for pain control after invasive bilateral third molar extractions. Int J Oral Maxillofac Surg 2017;46(5):621-627. DOI: 10.1016/j.ijom.2017.01.008.

7. Orozco-Solis M, Garcia-Avalos Y, Pichardo-Ramirez C, et al. Single dose of diclofenac or meloxicam for control of pain, facial swelling, and trismus in oral surgery. Med Oral Patol Oral Cir Bucal 2016;21(1):127134. DOI: 10.4317/medoral.20925.

8. Kulkarni DG, Salgia G, Shetty L. C-reactive protein estimation: a quantitative analysis for three nonsteroidal anti-inflammatory drugs: a randomized control trial. Indian J Dent Res 2015;26(1):43-47. DOI: 10.4103/0970-9290.156797.

9. Akbulut N, Üstüner E, Atakan C, et al. Comparison of the effect of naproxen, etodolac and diclofenac on postoperative sequels following third molar surgery: a randomised, double-blind, crossover study. Med Oral Patol Oral Cir Bucal 2014;19(2):149-156. DOI: 10.4317/ medoral.19518.

10. Mony D, Kulkarni D, Shetty L. Comparative evaluation of preemptive analgesic effect of injected intramuscular diclofenac and ketorolac after third molar surgery- a randomized controlled trial. J Clin Diagn Res [Internet] 2016;10(6):102-106. DOI: 10.7860/ JCDR/2016/17696.8045.

11. El-Sharrawy EA, El-Hakim IE, Sameeh E. Attenuation of C-reactive protein increases after exodontia by tramadol and ibuprofen. Anesth Prog 2006;53(3):78-82. DOI: 10.2344/0003-3006(2006)53[78:AOCPIA ]2.0.CO;2. 